\title{
A Review of Living Collections with Special Emphasis on Sustainability and Its Impact on Research Across Multiple Disciplines
}

\author{
Kevin McCluskey
}

Formal living collections have unique characteristics that distinguish them from other types of biorepositories. Comprising diverse resources, microbe culture collections, crop and biodiversity plant germplasm collections, and animal germplasm repositories are commonly allied with specific research communities or stakeholder groups. Among living collections, microbial culture collections have very long and unique life histories, with some being older than 100 years. Regulatory, financial, and technical developments have impacted living collections in many ways. International treaty obligations and restrictions on release of genetically modified organisms complicate the activities of living collections. Funding for living collections is a continuing challenge and threatens to create a two-tier system where medically relevant collections are well funded and all other collections are underfunded and hence understaffed. Molecular, genetic, and whole genome sequence analysis of contents of microbes and other living resource collections bring additional value to living collections.

Keywords: culture collection, living collection, microbial germplasm

\section{Introduction}

$\mathrm{F}_{\mathrm{b}}$ ORMAL LIVING COLLECTIONS are a special category of biological repository that differ from biobanks by holding resources that are generally capable of being reproduced ad infinitum $^{1,2}$ and this emphasizes that such collections should have long-term strategies for sustainability. While not all living collections can perpetuate the exact clonal organism, living collections of microbes, algae, and some plants have the ability to preserve and maintain organisms clonally over many decades without significant genetic changes. This is especially important for microbes, for plant and animal agricultural resources, and for biodiversity conservation. ${ }^{3,4}$ Collections of invertebrates, most plants, and vertebrates typically must passage individuals and therefore preserve the genetic characteristics, but not the unique individual, although longer generation times mean that individual genotypes may persist over many years or even decades. This is in stark contrast to most biobanks where each individual resource is finite and cannot be replicated. ${ }^{5}$

Formal living collections are often established with longterm preservation and ongoing quality control as primary goals, whereas biobanks are often established with explicit research goals, often related to specific diseases. ${ }^{6}$ Living collections may be established in support of a specific research area $^{1,2}$ or as a diverse taxonomy resource, ${ }^{7,8}$ and many culture collections have found new value as technology has advanced. ${ }^{9,10}$ Most living collections allow repurposing of holdings without the need for consent of the depositor, although some new uses may require benefit sharing under the Nagoya Protocol. ${ }^{11}$ Changing legal or regulatory circumstances requires collections to address issues of sustainability and the overall trend is toward increased impact through implementing best practices for quality management, data sharing, and visibility of validated and authenticated materials. ${ }^{12}$ Living collections are easily categorized into several classes (Table 1). Many are at risk because of insecurity of support.

\section{Microbe Biodiversity Collections}

Having been identified as the foundation of the coming white bioeconomy, ${ }^{13}$ and with a mandate from the Convention on Biological Diversity (CBD) for ex situ preservation of biodiversity, culture collections have become increasingly coordinated with shared best practices, ${ }^{14,15}$ data systems, ${ }^{16,17}$ and engagement with diverse genome programs. ${ }^{18,19}$ The global culture collection community interacts through the activities of the World Federation for Culture Collections (WFCC), which will commemorate its 70-year anniversary at the 14th International Conference on Culture Collections in 2017. As a Federation in the context of the

Fungal Genetics Stock Center, Department of Plant Pathology, Kansas State University, Manhattan, Kansas.

(C) Kevin McCluskey, 2017; Published by Mary Ann Liebert, Inc. This Open Access article is distributed under the terms of the Creative Commons Attribution Noncommercial License (http://creativecommons.org/licenses/by-nc/4.0/) which permits any noncommercial use, distribution, and reproduction in any medium, provided the original author(s) and the source are credited. 
Table 1. Classes of Living Collections

\begin{tabular}{|c|c|c|c|c|c|}
\hline Class & Holdings & Support & Host & Community & Sustainability \\
\hline Biodiversity & $\begin{array}{l}\text { Type and } \\
\text { environmental } \\
\text { accessions }\end{array}$ & $\begin{array}{l}\text { Institutional, } \\
\text { fee based }\end{array}$ & $\begin{array}{l}\text { Academic, } \\
\text { Industrial, } \\
\text { or clinical }\end{array}$ & $\begin{array}{l}\text { Taxonomy, } \\
\text { biodiversity, } \\
\text { or discovery }\end{array}$ & At risk \\
\hline Genetic & $\begin{array}{l}\text { Type specimens, } \\
\text { whole genome } \\
\text { sequenced lines, } \\
\text { mutant lines }\end{array}$ & $\begin{array}{l}\text { Government, } \\
\text { Institution, } \\
\text { or fee based }\end{array}$ & $\begin{array}{l}\text { Academic or } \\
\text { government }\end{array}$ & $\begin{array}{l}\text { Genetic, cell } \\
\text { biology, genomics } \\
\text { research }\end{array}$ & At risk \\
\hline $\begin{array}{l}\text { Research } \\
\quad \text { resource }\end{array}$ & $\begin{array}{l}\text { Manipulated, } \\
\text { engineered, } \\
\text { or highly } \\
\text { characterized lines }\end{array}$ & $\begin{array}{l}\text { Government, } \\
\text { intramural, } \\
\text { institution, } \\
\text { or fee based }\end{array}$ & $\begin{array}{l}\text { Academic } \\
\text { or government }\end{array}$ & $\begin{array}{l}\text { Genetic, cell } \\
\text { biology, genomics } \\
\text { research }\end{array}$ & At risk \\
\hline Agricultural & $\begin{array}{l}\text { Wild and improved } \\
\text { lines }\end{array}$ & Governmental & Governmental & $\begin{array}{l}\text { Crop and animal } \\
\text { breeding }\end{array}$ & Stable \\
\hline Medical & $\begin{array}{l}\text { Health-related } \\
\text { microbes, cell } \\
\text { lines, and related } \\
\text { resources }\end{array}$ & Government & $\begin{array}{l}\text { Contract } \\
\text { laboratory }\end{array}$ & Clinical, biodefense & Stable \\
\hline Patent (IDA) & $\begin{array}{l}\text { Microbes described } \\
\text { in patent }\end{array}$ & Government & $\begin{array}{l}\text { Independent or } \\
\text { housed at culture } \\
\text { collection }\end{array}$ & Industry & Self-sustaining \\
\hline
\end{tabular}

IDA, International Depository Authority.

International Union of Microbiological Societies, the WFCC has an advocacy role on behalf of culture collections around the world. The WFCC publishes a list of culture collections through its website (www.wfcc.info) and organized the WFCC World Data Centre for Microorganisms in 1972. ${ }^{20}$

One of the world's largest and most diverse living microbe collections, the American Type Culture Collection (ATCC), ${ }^{21}$ was originally established in 1925 at the McCormick Institute (Chicago, IL). Having received over $\$ 18,000,000$ in support from the NSF from 1954 until 2009 both directly and as collaborative projects, the ATCC holds over 18,000 bacterial strains, fungi, and yeasts representing 7600 species. The ATCC maintains and distributes over 500 microbial cultures certified as standards for quality control or as reference materials and is unique among U.S. culture collections in holding ISO certifications for quality management (9001:2008), as well as for the production of reference materials (ISO Guide 34 and ISO 17925). ${ }^{21}$ In addition to diverse microbial and mammalian cell culture material, the ATCC was the first International Depository Authority (IDA) for preservation of microbial germplasm described in patents under the Budapest Treaty. ${ }^{22}$ The ATCC also manages diverse collections under contract with the U.S. National Institutes of Health as well as the Joint Program Executive Office for Chemical and Biological Defense. The former includes the BEI (originally, Biology of Emerging Infections) resource collections established by the U.S. National Institute of Allergy and Infectious Diseases, which includes over 6000 Biosafety level 1 and 2 reagents, including bacteria, fungi, protozoa, viruses, and mutant strains, and related reagents (www.beiresources.org [accessed May 27, 2016]). Resources managed for the Department of Defense include the Critical Reagents Program (CRP), which includes essential high-quality validated reference material for assay and response development, as well as for detection and threat neutralization. The CRP has ISO certification for production of medical diagnostic material as well as quality management and ISO guide 34 reference material production. The CRP is un- ique among culture collections in having a formal plan for 30 years of sustainability, while BEI operates on a 7-year cycle. The ATCC has a mixed approach to sustainability. On one hand, their core collections depend on high demand by clients, an approach they reinforce by promoting the use of their material in formal industry standards for diagnosis and quality certification. The second approach to sustainability is to leverage their expertise to provide services to government clients with large microbial and related resource collections.

The agricultural and industrial microbiology communities are served by the U.S. Department of Agriculture (USDA) Agricultural Research Service (ARS) collection at the former Northern Region Research Laboratory (NRRL; Peoria, IL). While its holdings are taxonomically limited, the USDA NRRL collection is both a biodiversity collection as well as an IDA, and also a collection of agriculturally and industrially important microbes. ${ }^{23}$ Among other notable accomplishments, scientists at the NRRL collection are credited with isolating and distributing key strains for high levels of production of penicillin. ${ }^{24,25}$ The NRRL collection presently holds over 95,000 unique isolates and distributes between 6000 and 8000 strains annually, ${ }^{26}$ despite having only two full-time staff, well below international norms. ${ }^{27}$ As a reflection of these limited resources, the NRRL caps strain requests at 24 strains per year (http://nrrl.ncaur.usda.gov [accessed May 27, 2016]). The limit on strain requests is unusual among living microbe collections, but is a reflection of the small staffing at this highly impactful collection. The NRRL and other USDA collections such as the ARS Entomopathogenic Fungal Cultures collection ${ }^{28}$ and U.S. Forest Service collections ${ }^{29}$ face sustainability challenges, including staffing, space, and regulatory compliance, at least partially, because of how the USDA ARS funds research with fixed allocations despite rising costs. Challenging this model, U.S. government collections have a new mandate to develop longterm sustainability, access, and database resources according to a 2010 memo from the White House Office of Science and 
Technology Policy. ${ }^{30}$ This was reinforced by the America Competes $\mathrm{Act}^{31}$ and expanded in 2014 to include collections supported, but not owned, by the federal government. The USDA released a collection policy in $2014,{ }^{32}$ citing the Food, Agriculture, Conservation, and Trade Act of 1990 as their enabling legislation, and describing their policies for acquisition, preservation, deaccession, and availability of genetic resources as required under the 2010 OSTP memo.

Among other biodiversity-focused collections in the United States, the Phaff Yeast Culture Collection at the University of California, Davis, is notable for having survived the retirement of the founding curator. ${ }^{33}$ While the original intent of the collection was for yeast systematics, novel applications include the production of high-value lipids $^{34}$ and also the characterization of tolerance to ionic liquids for biomass deconstruction. ${ }^{35}$ With holdings of over 6000 strains, the Phaff collection is a leading global resource in the yeast biodiversity community. ${ }^{36}$ The Phaff Collection receives project support from the NSF, but depends on support from users and its host institution for longterm sustainability.

The World Phytophthora Resource at the University of California, Riverside, holds diverse isolates of the plant pathogenic Stramenopile Phytophthora as well as close relatives. These organisms are both significant economically $^{37}$ and also associated with significant human impact through plant disease, as seen during the Irish potato famine. ${ }^{38}$ Because of their tremendous negative impact on agricultural yields, Phytophthora and its relative organisms have been studied extensively both from ecological and taxonomic perspectives, ${ }^{39}$ and also with regard to the molecular mechanisms of plant-microbe interactions. ${ }^{40,41}$ Depending mostly on support from clients and the University of California, this collection has significant sustainability issues, largely related to the requirement for long-term cryopreservation of strains. While many of the isolates in this collection, and the DNA biobank, were supported by NSF funds, these were on a competitive nonrenewable basis and the collection presently has no external support. While enjoying tremendous support from its user community, there is no clear plan to sustain this collection when the present curator retires. Other valuable microbe collections hosted at U.S. universities include wine yeast and bacteria at UC Davis, wood-staining fungi at Oregon State, plant pathogenic bacteria and fungi at Penn State, Hawaii, and Nebraska, and Mollicutes at the University of Florida. ${ }^{29,42}$

With both microscopic and macroscopic accessions, the two collections holding valuable algal cultures in the United States maintain significant resources as well as expertise for working with these diverse aquatic organisms. The UTEX algal collection at the University of Texas in Austin holds freshwater algae, while the National Center for Marine Algae and Microbiota at the Bigelow Laboratory in Maine emphasizes marine organisms. These laboratories both received significant support from the US NSF over many years and are making progress on a path toward self-sufficiency, both through the sale of diverse algal products and also by engagement of their respective research and biofuel communities. $^{29,43}$ The UTEX collection was originally established at Indiana University in 1953 and moved to Texas in 1976. It holds over 3000 different strains from 200 different genera. Where possible, the cultures are maintained axenically, but some contain consortia. The NCMA has grown along with its host laboratory and moved into modern facilities in 2012. In addition to over 2600 strains of algae, the collection includes 75 bacterial cultures and is developing an algal virus resource, in keeping with the significant impact microbes can have on algal biology. ${ }^{44}$ To supplement their revenue, both algal collections offer diverse services, including private strain storage, application development, and strain identification. The NCMA is an IDA and provides storage for strains for patent purposes. Because an IDA has formal obligations under the Budapest Treaty ${ }^{22}$ (Table 1), the NCMA charges deposit fees up to $\$ 10,000$ for 30 -year culture of algae cited in patents.

\section{Genetic and Research Resource Collections}

Among several collections tied to specific research communities, the Fungal Genetics Stock Center (FGSC) has both biodiversity and research resource roles. ${ }^{45}$ The FGSC has accessions of over 3000 wild-type strains of filamentous fungi, including many from whole genome sequencing programs, as well as strains from 46 countries and also diverse locations within the United States, including Hawaii and Puerto Rico. In addition, the FGSC holds in a nonaccessioned manner, the entire collection of over 4500 wild-type Neurospora strains from the collection of David Perkins. ${ }^{46}$ As a research resource repository, the FGSC holds over 7300 classical mutant strains, including 1634 Aspergillus strains and over 7000 Neurospora strains. Since the advent of modern molecular gene manipulation, the FGSC has accessioned nearly 13,000 gene deletion mutants of Neurospora crassa. ${ }^{47}$

In addition to fungal strains, the FGSC pioneered the accession of molecular resources in the 1980s, including over 700 plasmids, dozens of ordered and pooled gene libraries, and more recently arrayed sets, typically of gene deletion mutants. While these are not formally accessioned, they include over 3500 Candida albicans homozygous gene deletion mutants ${ }^{48,49}$ and 6000 Cryptococcus neoformans gene deletion mutants. ${ }^{50-52}$ Nonaccessioned material in the FGSC collection includes a set of biochemical and sexual mutants of Allomyces, ${ }^{53}$ auxotrophic mutants of Ustilago, ${ }^{54}$ and over 48,000 tagged integrant mutant strains of Magnaporthe grisea. ${ }^{55}$ The FGSC was supported continuously by the US NSF from 1960 until 2014, and the end of support coincided with new research emphases as well as changes in funding at NSF. The loss of NSF funding and unavailability of funds from the host institution required that the FGSC move to a new host institution in 2014 and raise its fees from $\$ 20$ per strain in 2013 to $\$ 50$ per strain in 2015. This fee increase led to a reduction of strain distribution from 2635 individual strains in 2013 to 949 strains in 2015, although distribution of gene deletion mutants in arrayed sets remained a strong revenue center for the collection. ${ }^{56}$ Even with the revenue from these arrayed sets, the FGSC is unable to generate sufficient funds to pay the salaries of a curator and technician, a situation typical of most microbe collections.

The Coli Genetic Stock Center (CGSC) at Yale University is another example of an NSF-supported research resource collection closely tied to its research community. ${ }^{57}$ With nearly 10,000 strains in the public collection, the CGSC has a deep history in the management of both living resources as well as genetic information for work with $E s$ cherichia coli $\mathrm{K} 12$ strains. ${ }^{58}$ Unrelated to the CGSC, the E. coli reference center at Penn State University provides identification and characterization of wild $E$. $\operatorname{coli}^{59,60}$ and 
charges fees for these services to support their activities. Both the CGSC and the reference center face significant sustainability challenges. The CGSC has addressed these challenges by accessioning novel resources, including strains carrying fluorescent protein-gene fusions, and gene deletion mutants. These sustainability challenges have been longstanding; the CGSC first instituted user fees in 1988 and charges different fees for nonprofit or for-profit clients.

Similarly, the Bacillus Genetic Stock Center (BGSC) at the Ohio State University is closely tied to the Bacillus subtilis research community ${ }^{61}$ and serves as both a strain ${ }^{62}$ and information resource. ${ }^{63}$ Within its mandate, the BGSC has type strains for 34 Bacillus species as well as nearly 2000 strains, including mutants and reference strains. As part of the NSF living collection program for many years, the BGSC has never held or distributed strains or derived products from Bacillus anthracis. As public funding for living microbe collections has decreased, the BGSC has looked to novel strain types and collections for enhancing revenue. New resources such as genomic DNA, plasmids, a gene knockdown library, whole genome strains, and strains with enhanced biotechnological potential offer revenue opportunities (www.bgsc.org [accessed August 31, 2016]).

The Chlamydomonas Resource Center is the only public collection dedicated to this research community and holds 4000 classical mutant and wild-type strains, as well as plasmids for use with Chlamydomonas. In 2016, the Chlamy center added 37,000 mutants from a molecular mutant library ${ }^{64}$ to expand holdings and enhance revenue. With longterm support from the NSF, the Chlamy center moved from its original home at Duke University to the University of Minnesota in 2004. While moving to a per-strain fee system, the Chlamy center still offers strain subscriptions to simplify requests. Like other collections historically supported by the NSF, the Chlamy center is increasingly dependent on user fees for its operations, a situation that places resources required for an entire research community at risk.

\section{Diverse Plant and Animal Collections}

While many plant collections are available for research, most plant collections are herbaria that hold preserved, fixed taxonomic specimens. Additional public plant collections include botanic and public gardens, which are important for preserving a record of plant biodiversity, but do not have a significant role in distributing living specimens for breeding, research, or education. ${ }^{65}$ The USDA National Plant Germplasm System (NPGS), established under USDA ARS National Program 301, maintains and shares essential plant and animal germplasm for crop ${ }^{66,67}$ and livestock production. ${ }^{68,69}$ The USDA NPGS comprised 19 National Germplasm Repositories as well as crop-specific collections and the National Arboretum. These collections share a central backup facility for long-term preservation of plant germplasm (as well as select animal and microbe stocks) at the National Laboratory for Genetic Resource Preservation (NLGRP; Ft. Collins, CO). With combined holdings of over half a million accessions, including fifteen thousand species, the USDA NPGS holds crop and crop-relative germplasm to insure availability of genetic diversity to respond to changes in climate, pest, and pathogen characteristics. The germplasm repositories maintain plantings of diverse varieties and accessions of plants relevant to the local climate, and can provide them to re- searchers and breeders through the USDA Germplasm Resources Information Network (GRIN; www.ars-grin.gov), which includes the ability to request germplasm resources for research and breeding.

In addition, the USDA maintains the Maize Genetics Cooperation Stock Center (COOP) at the University of Illinois at Urbana-Champaign. With its roots in the 1929 publication of a maize linkage map by Rollins Emerson and George Beadle, the Maize COOP now includes 100,000 individually pedigreed stocks, including chromosome aberrations, generated by exposure to atomic bomb tests in 1946 and 1948 in the south Pacific. ${ }^{70}$ Most of the resources in the Maize COOP collection are not directly agronomically useful, but have been cited in over 40,000 publications. Similar to the genetic resources in the Maize COOP, resources for work with the model plants are available through the Arabidopsis Biological Resource Center (ABRC) at the Ohio State University. Originally established in 1991 and receiving support from the NSF, ABRC now holds over one million stocks, as well as complementary DNA (cDNA) clones and gene libraries of Arabidopsis and related species. With the associated Arabidopsis Information Resource (TAIR), the ABRC provides a comprehensive resource for plant research. ${ }^{71}$

While a comprehensive survey of plant resources is beyond the scope of the present review, special mention of the Wheat Genetics Resource Center (WGRC) is merited. With a long history of holding and sharing diverse wheat germplasm for crop improvement and to provide a diverse genetic base, the WGRC maintains nearly 5000 stocks representing different species as well as stocks with defined cytogenetic characteristics, and an extensive information resource for genetic and genomic work with wheat. ${ }^{72}$ Other plant germplasm conservation systems include the Consultative Group on International Agricultural Research (CGIAR), which coordinates 15 crop germplasm research and preservation centers around the world (www.cgiar.org), and the Crop Trust, with the Svalbard Global Seed Vault. ${ }^{73}$ Additional plant resources are maintained at botanical and public gardens and through community and heirloom seed organizations. ${ }^{74-76}$

Most living animal collections in the United States focus on animals as models of human disease and receive support from the NIH Office of Research Infrastructure Programs (ORIP; http://dpcpsi.nih.gov/orip). These include nonhuman primates, rodents, and aquatic models from the Ambystoma salamander, which has the ability to regenerate limbs, to the zebrafish, noted for its utility in developmental biology and behavior studies. One of the most well-known and successful model animal collections is the Jackson Laboratory, which holds stocks of the laboratory mouse, Mus musculus. With modern facilities in Maine and California, the Jackson Laboratories was founded in 1929 and has contributed to over 225,000 publications and patents as well as 26 Nobel Prizes. Funding for animal models of human disease was reinforced in the 2016 strategic plan of the NIH ORIP, which commits to developing and maintaining cutting-edge resources through 2020 (https://dpcpsi.nih.gov/ sites/default/files/ORIP\%20Strategic\%20Plan\%20Final-\%20 April\%202016.pdf).

Most production of animal germplasm is maintained in the private sector, including swine, cattle, and poultry ${ }^{68}$ To protect this valuable germplasm, the USDA maintains backups of valuable animal resources at its Ft. Collins NLGRP facility, although this program faces challenges of scope, proximity, and community engagement. ${ }^{77}$ 
Also supported by the US NSF, the Duke Lemur Center (DLC) spans the divide between an ex situ biodiversity center and a tissue repository. ${ }^{81}$ Anticipating its 50th anniversary in 2016, the DLC maintains a colony of 250 individual living lemurs across 21 species. With historical holdings of nearly 4000 individual prosimian primates since its founding on 80 acres near Duke University in 1966, the DLC has a variety of research and outreach activities for scientists and the general public. ${ }^{81}$

Invertebrate animal collections include resources maintained in support of diverse health and research-related communities. Invertebrate collections for health research include those maintained by the U.S. Centers for Disease Control and Prevention through their Animal Resources Branch. These are important for studies of vector-transmitted infections, including arboviral or bacterial diseases. While extensive, these are not public, but are essential for diagnostic testing and understanding disease outbreak characteristics and spread. Similarly, the USDA maintains collections of living and onceliving invertebrates (typically preserved in alcohol) for study of the transmission of agriculturally important plant and animal diseases. These collections are often small and maintained at research facilities such as the Biological Control Research Insect collection in Manhattan, KS, the Aphid Biotype and Natural Enemy collection in Stillwater, OK, or the Mexican Fruit Fly collection in Fargo, ND. ${ }^{78}$

Other invertebrate collections, such as the Drosophila Species Stock Center ${ }^{79}$ at University of California, San Diego, or the Bloomington Drosophila Stock Center ${ }^{80}$ have biodiversity and genetic missions, respectively. The Drosophila Species collection has support for its taxonomic, genomic, and biodiversity-related mission through the NSF Collections in Support of Biological Research (CSBR) program, as well as support from users. To address sustainability issues, the Drosophila Species collection has relocated several times, and will move again in 2017. The larger Bloomington Drosophila Stock Center was originally established at Caltech in 1934 with a catalog of 572 D. melanogaster stocks and has diverse support through the NIH Office of the Director as well as from user fees, and historical support through the NSF and the Howard Hughes Medical Institute. With holdings of over 53,000 stocks, the Bloomington Drosophila Stock Center ${ }^{80}$ is a global leader with annual distribution of nearly a quarter of a million samples in 2015 (http://flystocks.bio.indiana.edu [accessed June 8, 2016]).

\section{Regulatory Issues}

International efforts mandated by treaties such as the CBD, its subsidiary agreements, including the Cartagena Protocol on Biosafety and the Nagoya Protocol on Access and Benefit Sharing, or the International Treaty on Plant Genetic Resources for Food and Agriculture, ${ }^{82}$ have impacted the availability of living resources, including microbe, ${ }^{83}$ plant $^{84}$ and animal ${ }^{85}$ germplasm important for production of food, feed, and fiber. The Nagoya Protocol mandates that benefits from genetic resource utilization, including noncommercial research use, be returned to the country or community of origin and calls upon each party (country) to enact national legislation. While the European Union and Brazil have enacted national legislation, most countries have yet to respond to the Nagoya protocol. The immediate effect of these changes in regulations is sig- nificant uncertainty about how to comply. One immediate impact is that the number of deposits of microbial resources has decreased since the Nagoya Protocol began ratification. ${ }^{86}$ Similarly, the requirement for material accession agreements has required the donor institution to approve any deposits and because of this, resources with diverse histories may require multiple institutions' approval. The decrease of accessions impacts sustainability for collections that depend on fees for support. ${ }^{86}$ Moreover, limits to accession can impact the ability of collections to maintain sufficient populations to avoid the problem of genetic drift. ${ }^{87,88}$

To address the impact of international treaties, including the CBD and the Nagoya Protocol on Access and Benefit Sharing, ${ }^{11}$ several organizations have developed networks to promote harmonization among collections. Beginning with the Global Biological Resource Center Network demonstration project $^{89}$ and culminating with the EU Microbial Research Resources Infrastructure, ${ }^{90}$ and with national and regional collection networks under development in Belgium, Asia, Korea, Japan, South America, the European Union, and the United States $^{29}$ (www.wfcc.info/collections/networks), access to catalogs of well-characterized resources with documented provenance is at a level never before attained. ${ }^{91}$ Still, the requirements imposed by the Nagoya Protocol, and by the Cartagena protocol for biosecurity, make it more important than ever that genetic resources are exchanged by official channels and not on an ad hoc, peer to peer basis. ${ }^{92} \mathrm{Di}-$ verse agencies regulate the exchange of living organisms, including the U.S. Centers for Disease Control, the International Air Transport Association, the International Civil Aviation Organization, the U.S. Department of Transportation, and the USDA Animal and Plant Health Inspection Service (APHIS) Plant Protection and Quarantine office. In the United States, genetically modified plant pathogenic microorganisms are further regulated by the USDA APHIS Biotechnology Regulatory Services. In addition to national permit requirements and the requirements of the Cartagena Protocol on Biosafety for the exchange of genetically engineered organisms, international exchange of genetic resources may be limited by the Wassenaar Arrangement on Export Controls for Conventional Arms and Dual-Use Goods and Technologies. ${ }^{93}$ Microbes such as the rice pathogens $M$. grisea and Xanthomonas oryzae, the wheat pathogen Puccinia graminis, or other select agent microbes cannot be exported without special permits. While the exchange of materials may be limited by these regulations in the era of next-generation DNA sequencing, the genome sequence can generally be published and exchanged freely. ${ }^{94-96}$

\section{Funding and Sustainability for Living Repositories}

Living microbe repositories are established for different reasons and have funding related to their intent. For example, article 9 of the CBD mandates that every party (typically a country) have an ex situ microbial germplasm repository to manage the microbial diversity unique to that entity. ${ }^{97}$ In the United States, the National Science Foundation supported diverse living collections, termed Living Stock Collections, for many years and required robust quality control and operational oversight by an external advisory board. Many of the collections supported by this program were closely tied to specific research communities. Examples include the 
CGSC, which held strains and managed the genetic map for $E$. coli, the FGSC, which held mutants of the two main model filamentous fungi, Aspergillus nidulans and $N$. crassa, and coordinated genetic maps and meetings, ${ }^{98}$ as well as the Bacillus Genetics Stock Center, and the Chlamydomonas Resource Center. In 2011, the NSF combined its living and once-living collection programs, and in 2016 briefly closed the program to applications sparking an outcry from the living and natural history collection communities. ${ }^{99,100} \mathrm{Si}$ milarly, while the US NIH supported diverse research resource collections through the Division of Microbiology and Infectious Diseases for many years, these programs have undergone significant reorganization in recent years. Many $\mathrm{NIH}$-supported microbial resources were centralized into the Microbiology and Infectious Diseases Biological Research Resources (MID-BRR) Program in $2009^{101}$ and in 2012, the NIH closed their National Center for Research Resources (P.L. 112-74). Remaining NIH support for research resources is presently distributed through diverse programs.

Most open living collections depend on public support, although many derive revenue from resource sales, contract research, and the development and licensing of research outputs. ${ }^{27}$ According to the World Data Centre for Microorganisms, ${ }^{17}$ of 708 microbial collections around the world, only 67 have industry or private support and 277 are supported by local government, 57 have combined semigovernmental and university support, and 278 are solely supported by their host university (www.wfcc.info/ccinfo/ statistics [accessed July 20, 2016]). With diverse agencies providing support for collections, significant differences exist related to the collection holdings and community served. A recent report described federal collections in the United States and identified a small percentage (around $10 \%$ ) that held living resources. ${ }^{102}$

While some U.S. collections are supported publicly, in most cases, this support does not meet best practice recommendations such as those by the Organization for Economic Cooperation and Development ${ }^{14}$ or the International Society for Biological and Environmental Repositories ${ }^{103}$ as follows: these best practice guidelines mandate staffing sufficient to manage the quality control, information technology, security, and biodiversity held in each collection and suggest that a modest sized collection (5000-10,000 accessions) would have at least six full-time staff. ${ }^{27}$ While the ATCC has multiple certifications for their collection management, their biodiversity collection is self-supporting and therefore depends on robust demand. The NIH-supported BEI collection (incorporating the MID-BRR collection), by way of contrast, has over 40 full-time staff lines fully funded by contract ${ }^{101}$ and does not charge fees for the end user, meaning that researchers in areas served by this collection can use grant funds for their own work rather than to obtain research resources. The USDA NRRL collection, with only one full-time curator and one research assistant, limits the number of strains available to any individual on an annual basis, a practice that can impact the ability to conduct broad studies in biodiversity, taxonomy, or the geographic range of valuable or dangerous traits.

Overall, most formal living collections have three major approaches to financial sustainability. These are long-term public support, project grant support, and end-user fees. ${ }^{27}$ While some collections provide services such as long-term storage, identification, or contract research in addition to their main mission, not all collections can offer these diverse services and may be limited by their funding, staffing, or sustainability. The mode of support is often related to the formal ownership of the collection, with government-owned collections usually prohibited from charging user fees.

Ad hoc collections are even more limited in the services they can provide, typically do not have formal quality control practices or dedicated facilities, and so it is difficult for such collections to persist after the retirement of the principal investigator. Exacerbating the challenges in obtaining funding, living collections have faced difficulties in making their voices heard both because they are numerically few and because most living collections are focused on their own unique stakeholder communities. For example, in the United States, culture collections have historically interacted through the United States Federation for Culture Collections (USFCC), although this group ceased activities in $2000 .^{29}$ Complicating collaboration among living collections, most interactions occur with stakeholders at their discipline-specific meetings, such as the American Society for Microbiology, the Society for Industrial Microbiology and Biotechnology, and the American Phytopathological Society, among others. Since the USFCC ceased its activities, culture collections in the United States have no forum for interactions. Following leadership by an ad hoc committee within the American Phytopathological Society, ${ }^{104}$ a group of collection curators and stakeholders received a grant from the NSF for a Research Coordination Network and this group, acting under the heading U.S. Culture Collection Network (www.usccn.org), has held meetings at several public collections located at university and USDA sites. ${ }^{2,42,105}$ This network has allowed for several significant improvements to the security and sustainability of living microbe collections, such as coordinated off-site backup at the USDA NLGRP, ${ }^{29}$ and has included discussions of shared information resources, regulatory affairs, ${ }^{105}$ and engagement with the genome research community. ${ }^{42}$ This progress is valuable, but also has served to emphasize the vulnerability of many living collections to lapses in funding, to retirements and superficial changes in research emphases. ${ }^{29}$ The United States Culture Collection Network (USCCN) has recently engaged with a broader living collection community ${ }^{29}$ and is participating in ongoing activities to reinforce connections among formal living collections.

\section{Recommendations}

Because many culture collections grow organically through personal research collections, becoming the foundation for a larger community-specific collection, culture collections are often supported through the research project of the curator. ${ }^{106}$ Moreover, there is no formal policy on deposit of material by granting agencies and so many resources are only available through ad hoc transfer from the laboratory of the originator. This means that there are typically no quality control measures in place to insure the validity of the materials. Similarly, ad hoc exchanges are often done without regard to requirements on containment, packaging, or traceability. To combat this, simple measures can be enacted, in a manner similar to the establishment of requirements that DNA sequence be deposited in public databases. ${ }^{107}$ To start, fully funding the USDA NRRL collection as well as the historically NSF-supported collections, and allied university collections, would remove the funding bias, where medically relevant collections are fully funded 
and do not charge user fees, agriculturally relevant collections are marginally funded and restrict distribution to control costs, and biodiversity- or research system-specific collections are required to charge fees for the end user.

To ensure that a robust living collection system is available to support diverse research and development, a number of simple measures that have been described in a number of places $^{2,6,27,108}$ would ensure that research materials developed with public support are available to allow replication of controversial research results, to build upon valuable preliminary results, and to allow commercialization of resources as technology develops. ${ }^{109}$

Funding agencies should require that all living resources generated through publicly supported research are deposited in open public collections at the end of each grant period as part of every grant's materials management plan as is already required for data management. ${ }^{110}$

Funding agencies should encourage journal publishers to require an accession number from a public repository before publication. Similarly, journal publishers should be educated about regulatory issues and permit numbers should be published for research involving international exchanges, pathogenic organisms, or field releases of genetically modified organisms, as is already done for human studies. ${ }^{111}$

A unique persistent identifier, such as DOI, should be developed for living biological research resources to allow permanent tracking of biological resources. This is in contrast with the existing situation where material shared among multiple collections may be clonal, but have independent accession numbers, causing confusion and confounding direct comparison or benefit sharing. ${ }^{91}$

Living collections should be engaged by regulatory agencies to facilitate research with regulated materials. This component is essential because it would simplify regulatory compliance, an approach that was successfully implemented for managing Material Transfer Agreement issues by the plasmid bank, Addgene. ${ }^{112}$

Collections should seek and obtain external certifications appropriate to their activities (e.g., most client and data keeping should be certified to ISO 9001:2008). ${ }^{15}$

Stable funding for collections should be provided to ensure that well-trained staff are available and can develop relevant institutional memories. ${ }^{27}$

Collection staff should be encouraged to conduct research on the materials in the collection, ensuring that they have the expertise to identify and manipulate the living materials in the collection. ${ }^{14,15}$

As was done for plant genetic resources, ${ }^{113}$ one approach is to develop centrally coordinated distributed networks, taking advantage of distributed expertise at universities and research institutes. ${ }^{104}$ These networks should have permanent longterm support and should be subject to ongoing evaluation. Within the network, different collections should have positive incentive to participate to established norms, as described by best practice guidelines. ${ }^{14,103}$ Similarly, support for collections within the network should be critically evaluated on a regular cycle (5-7 years) to ensure best practices, relevancy, and other operational criteria. ${ }^{15}$ Importantly, as an infrastructure element, this needs to be publicly supported and resources held in trust for the public. The Belgian Coordinated Collections of Micro-organisms network (http:// bccm.belspo.be) ${ }^{114}$ and the U.S. Plant Germplasm System (www.ars-grin.gov/npgs) ${ }^{113}$ are good examples of networked collections. Implementation of these recommendations will require that collections, and most importantly collection users, advocate on behalf of the maintenance of resource collections. This advocacy can be through scientific societies ${ }^{104}$ or collection organizations, ${ }^{29}$ or like the responses made by diverse groups in response to the NSF collection funding hiatus in $2016 .{ }^{99,100}$

\section{Conclusions}

Formal living collections have a long history of making significant contributions in diverse areas of science. ${ }^{12}$ However, with stakeholder communities representing vertebrate and invertebrate animals, biodiversity, and crop plants, microbes, and algae, collections have historically found it difficult to speak with a common voice over many years. ${ }^{29}$ Because of this, some types of collections continually face sustainability challenges due to shortfalls in funding, which translate to difficulties in maintaining adequate staff, challenges in training staff, and degradation in facilities. ${ }^{29}$ While some technological advances, such as molecular genetics and genome sequence analysis, have reemphasized the value of collection holdings, not all collections are able to benefit from these advances. Similarly, there is a growing concern that whole genome sequence is being generated on material that is not publicly available. ${ }^{115-117}$ Moreover, regulatory issues, including those imposed by international treaties like the Nagoya Protocol on Access and Benefit Sharing, as well as biosecurity issues related to human, animal, and plant health impose new compliance burdens on collection staff. Adding to these challenges, the need to develop new approaches to sustaining collections, through innovative changes in collection marketing, distribution, and value added to collection holdings, has required collection staff to divert their attention away from research activities. ${ }^{2,27}$ While some research systems are supplanted by changes in technology or by advances in knowledge, others, especially biodiversity collections, hold materials that can never be replaced. Diverse living collections are the guardians of characterized germplasm for agricultural and health research, and are the foundation of the biotechnology revolution. ${ }^{13}$

\section{Acknowledgments}

This is contribution No. 16-365-J from the Kansas Agricultural Experiment Station. Partial support for publication charges was provided by grant DBI 1534564 from the U.S. National Science Foundation. The author wishes to express gratitude to the anonymous reviewers who have contributed to this article.

\section{Author Disclosure Statement}

No competing financial interests exist.

\section{References}

1. Smith D. Culture collections. Adv Appl Microbiol 2012; 79:73-118.

2. Stackebrandt E. Diversification and focusing: Strategies of microbial culture collections. Trends Microbiol 2010;18: 283-287.

3. Wildt DE. Genome resource banking for wildlife research, management, and conservation. ILAR J 2000;41:228-234. 
4. McDonald BA. The population genetics of fungi: Tools and techniques. Phytopathology 1997;87:448-453.

5. Gee S, Oliver R, Corfield J, Georghiou L, Yuille M. Biobank finances: A socio-economic analysis and review. Biopreserv Biobank 2015;13:435-451.

6. DiEuliis D, Johnson KR, Morse SS, Schindel DE. Opinion: Specimen collections should have a much bigger role in infectious disease research and response. Proc Natl Acad Sci U S A 2016;113:4-7.

7. Bull CT, Koike ST. Practical benefits of knowing the enemy: Modern molecular tools for diagnosing the etiology of bacterial diseases and understanding the taxonomy and diversity of plant pathogenic bacteria. Annu Rev Phytopathol 2015;53:157-180.

8. Boundy-Mills KL, Glantschnig E, Roberts IN, et al. Yeast culture collections in the twenty-first century: New opportunities and challenges. Yeast 2016;33:243-260.

9. McCluskey KW, Wiest A, Boundy-Mills K. Genome data drives change at culture collections. In: Nowrousian M, Esser K (eds). The Mycota XIII, Fungal Genomics. Berlin: Springer Verlag; 2014;4:81-96.

10. Sitepu IR, Sestric R, Ignatia L, et al. Manipulation of culture conditions alters lipid content and fatty acid profiles of a wide variety of known and new oleaginous yeast species. Bioresour Technol 2013;144:360-369.

11. Dedeurwaerdere T, Broggiato A, Manou D. Global scientific research commons under the Nagoya protocol: Governing pools of microbial genetic resources. In: Kamau E, Winter G, eds. Common Pools of Genetic Resources: Equity and Innovation in International Biodiversity Law. EarthscanRoutledge; 2013.

12. Stern S. Biological Resource Centers: Knowledge Hubs for the Life Sciences, 1st ed. Washington, DC: Brookings Institution Press; 2004: vii, 128.

13. Wald, S. Biological Resource Centres - Underpinning the Future of Life Sciences and Biotechnology. Organisation for Economic Development and Cooperation. Paris, 2001. Available at: https://www.oecd.org/sti/biotech/2487422.pdf Accessed November 8, 2016.

14. OECD SGot. OECD Best Practice Guidelines for Biological Resource Centres. Paris, France: OECD; 2007.

15. WFCC. World Federation for Culture Collections guidelines for the establishment and operation of collections of cultures of microorganisms 2010. 2010, 3rd ed. Available at: www.wfcc.info/guidelines Accessed November 8, 2016.

16. Ma J, Sugawara H. Activities of World Federation for Culture Collections (WFCC) World Data Centre for Microorganisms (WDCM). Microbiol Cult Coll 2011;27: 79-81.

17. Wu L, Sun Q, Sugawara H, et al. Global catalogue of microorganisms (GCM): A comprehensive database and information retrieval, analysis, and visualization system for microbial resources. BMC Genomics 2013;14:1.

18. Kyrpides NC, Hugenholtz P, Eisen JA, et al. Genomic encyclopedia of bacteria and archaea: Sequencing a myriad of type strains. PLoS Biol 2014;12:e1001920.

19. Stajich JE. 11 Phylogenomics enabling genome-based mycology. In: McLaughlin, Spatafora, eds. Systematics and Evolution. Berlin, Heidelberg: Springer; 2015: 279294.

20. Skerman V. Statement on the WFCC Center for storage, retrieval, and classification of data on microorganisms. Int J Syst Evol Microbiol 1973;23:477-479.

21. Simione F. In: Uhlir PF, ed. American Type Culture Collection: A Model for Biological Materials Resource
Management. National Research Council (US) Board on Research Data and Information. Washington, DC: National Academies Press (US); 2011.

22. Regulations BT. Budapest Treaty on the International Recognition of the Deposit of Microorganisms for the Purposes of Patent Procedure. Geneva: World Intellectual Property Organization; 1977.

23. Kurtzman CP, Bennett RA. Microbial collections key to unlocking new discoveries. Agric Res 2008;56:2.

24. Kaplan JK. A Culture of innovation. Agric Res 2016;64:1.

25. Neushul P. Science, government and the mass production of penicillin. J Hist Med Allied Sci 1993;48:371-395.

26. Ward TJ, ed. Overview of the ARS Culture Collection. Meeting Abstract, US Culture Collection Network. USDA NRRL; 2013. Available at: www.usccn.org/activities/ Documents/Abstracts_USCCNWorkshop_Peoria.pdf Accessed November 8, 2016.

27. Smith D, McCluskey K, Stackebrandt E. Investment into the future of microbial resources: Culture collection funding models and BRC business plans for biological resource centres. Springerplus 2014;3:81.

28. Humber R, Hansen K, Wheeler M. ARSEF USDA-ARS Collection of entomopathogenic fungal cultures: Catalog of species. 2014. Available at: https://www.ars.usda.gov/ ARSUserFiles/80620520/ALL\%20AVAIL\%2016Jan2014 .pdf Accessed November 8, 2016.

29. McCluskey K, Alvarez A, Bennett R, et al. The US culture collection network lays the foundation for progress in preservation of valuable microbial resources. Phytopathology 2016;106:532-540.

30. Memorandum to the heads of executive departments and agencies. 2010.

31. America COMPETES Reauthorization Act of 2010. 2010.

32. Service AR. Scientific Collections Management and Access Policy. Beltsville, MD: U.S. Department of Agriculture; 2014.

33. Boundy-Mills K. The Phaff yeast culture collection has found its niche. Soc Ind Microbiol News 2008;58:49-56.

34. Sitepu IR, Jin M, Fernandez JE, da Costa Sousa L, Balan $\mathrm{V}$, Boundy-Mills KL. Identification of oleaginous yeast strains able to accumulate high intracellular lipids when cultivated in alkaline pretreated corn stover. Appl Microbiol Biotechnol 2014;98:7645-7657.

35. Sitepu IR, Shi S, Simmons BA, Singer SW, Boundy-Mills $\mathrm{K}$, Simmons CW. Yeast tolerance to the ionic liquid 1ethyl-3-methylimidazolium acetate. FEMS Yeast Res 2014;14:1286-1294.

36. Boundy-Mills K. Yeast culture collections of the world: Meeting the needs of industrial researchers. J Ind Microbiol Biotechnol 2012;39:673-680.

37. Grünwald NJ, Garbelotto M, Goss EM, Heungens K, Prospero S. Emergence of the sudden oak death pathogen Phytophthora ramorum. Trends Microbiol 2012;20:131-138.

38. Haas BJ, Kamoun S, Zody MC, et al. Genome sequence and analysis of the Irish potato famine pathogen Phytophthora infestans. Nature 2009;461:393-398.

39. Ristaino JB, Madritch M, Trout CL, Parra G. PCR amplification of ribosomal DNA for species identification in the plant pathogen genus Phytophthora. Appl Environ Microbiol 1998;64:948-954.

40. Jiang RH, Tripathy S, Govers F, Tyler BM. RXLR effector reservoir in two Phytophthora species is dominated by a single rapidly evolving superfamily with more than 700 members. Proc Natl Acad Sci U S A 2008;105:48744879 . 
41. Qiao Y, Shi J, Zhai Y, Hou Y, Ma W. Phytophthora effector targets a novel component of small RNA pathway in plants to promote infection. Proc Natl Acad Sci U S A 2015;112:5850-5855.

42. Boundy-Mills K, Hess M, Bennett AR, et al. The United States Culture Collection Network (USCCN): Enhancing microbial genomics research through living microbe culture collections. Appl Environ Microbiol 2015;81:56715674.

43. Yu J, Liberton M, Cliften PF, et al. Synechococcus elongatus UTEX 2973, a fast growing cyanobacterial chassis for biosynthesis using light and $\mathrm{CO}_{2}$. Sci Rep 2015;5.

44. Van Etten JL, Dunigan DD. Chloroviruses: Not your everyday plant virus. Trends Plant Sci 2012;17:1-8.

45. McCluskey K. From genetics to genomics: Fungal collections at the Fungal Genetics Stock Center. Mycology 2011;2:161-168.

46. Turner BC, Perkins DD, Fairfield A. Neurospora from natural populations: A global study. Fungal Genet Biol 2001;32:67-92.

47. Colot HV, Park G, Turner GE, et al. A high-throughput gene knockout procedure for Neurospora reveals functions for multiple transcription factors. Proc Natl Acad Sci U S A 2006;103:10352-10357.

48. Nobile CJ, Mitchell AP. Large-scale gene disruption using the UAU1 cassette. In: Cihlar RL, Calderone RA, eds. Candida albicans: Methods and Protocols. Springer; 2009: 175-194.

49. Noble SM, French S, Kohn LA, Chen V, Johnson AD. Systematic screens of a Candida albicans homozygous deletion library decouple morphogenetic switching and pathogenicity. Nat Genet 2010;42:590-598.

50. Nelson RT, Pryor BA, Lodge JK. Sequence length required for homologous recombination in Cryptococcus neoformans. Fungal Genet Biol 2003;38:1-9.

51. Liu OW, Chun CD, Chow ED, Chen C, Madhani HD, Noble SM. Systematic genetic analysis of virulence in the human fungal pathogen Cryptococcus neoformans. Cell 2008;135:174-188.

52. Chun CD, Madhani HD. Ctr2 links copper homeostasis to polysaccharide capsule formation and phagocytosis inhibition in the human fungal pathogen Cryptococcus neoformans. PLoS One 2010;5:e12503.

53. Olson LW. Allomyces-A different fungus. Opera Botanica 1984;73:1-96.

54. Perkins DD. Biochemical mutants in the smut fungus Ustilago maydis. Genetics 1949;34:607-626.

55. Betts MF, Tucker SL, Galadima N, et al. Development of a high throughput transformation system for insertional mutagenesis in Magnaporthe oryzae. Fungal Genet Biol 2007;44:1035-1049.

56. McCluskey K, Leslie JF. New prospects, progress, and research at the Fungal Genetics Stock Center. Phytopathology 2015;105(Suppl 4):S4.91.

57. Bachmann BJ. Derivations and genotypes of some mutant derivatives of Escherichia coli K-12. In: Neidhardt FC, ed. Escherichia coli and Salmonella: Cellular and Molecular Biology, 2nd ed. Washington, DC: ASM Press; 1996: 2460-2488.

58. Bachmann BJ, Low KB, Taylor AL. Recalibrated linkage map of Escherichia coli K-12. Bacteriol Rev 1976;40:116.

59. Losada L, DebRoy C, Radune D, et al. Whole genome sequencing of diverse Shiga toxin-producing and nonproducing Escherichia coli strains reveals a variety of virulence and novel antibiotic resistance plasmids. Plasmid 2016;83:8-11.

60. DebRoy C, Fratamico PM, Yan X, et al. Comparison of $\mathrm{O}$-antigen gene clusters of all O-serogroups of Escherichia coli and proposal for adopting a new nomenclature for O-typing. PloS One 2016;11:e0147434.

61. Carlson CR, Caugant DA, Kolst $\varnothing$ AB. Genotypic diversity among Bacillus cereus and Bacillus thuringiensis strains. Appl Environ Microbiol 1994;60:1719-1725.

62. Zeigler DR. Bacillus Genetic Stock Center Catalog of Strains, Volume 1: Bacillus subtilis 168. Bacillus Genetic Stock Center; 2000. Available at: http://www.bgsc.org/ catalogs.php Accessed November 8, 2016.

63. Zeigler DR, Prágai Z, Rodriguez S, et al. The origins of 168, W23, and other Bacillus subtilis legacy strains. J Bacteriol 2008;190:6983-6995.

64. Li X, Zhang R, Patena W, et al. An indexed, mapped mutant library enables reverse genetics studies of biological processes in Chlamydomonas reinhardtii. Plant Cell 2016:28:367-387.

65. Maxted N, Ford-Lloyd B, Hawkes J. Complementary conservation strategies. In: Maxted N, Ford-Lloyd BV, Hawkes JG, eds. Plant Genetic Conservation: The In Situ Approach. Springer; 2000: 15-39.

66. Volk GM, Richards CM. Availability of genotypic data for USDA-ARS National Plant Germplasm System accessions using the genetic resources information network (GRIN) database. HortScience 2008;43:13651366.

67. Elstein D. ARS is banking on germplasm. Agric Res 2003; 51:12.

68. Blackburn H. Integrating policies for the management of animal genetic resources with demand for livestock products and environmental sustainability. Anim Genet Resour Inform 2007;41:53-64.

69. Blackburn H, Plante Y. North American animal breeding and production: Meeting the needs of a changing landscape. J Anim Breed Genet 2014;131:247-248.

70. Kass LB, Bonneuil C, Coe EH. Cornfests, cornfabs and cooperation: the origins and beginnings of the maize genetics cooperation news letter. Genetics 2005;169:17871797.

71. Rhee SY, Beavis W, Berardini TZ, et al. The Arabidopsis Information Resource (TAIR): A model organism database providing a centralized, curated gateway to Arabidopsis biology, research materials and community. Nucleic Acids Res 2003;31:224-228.

72. Tiwari VK, Heesacker A, Riera-Lizarazu O, et al. A whole-genome, radiation hybrid mapping resource of hexaploid wheat. Plant J 2016;86:195-207.

73. Westengen OT, Jeppson S, Guarino L. Global ex-situ crop diversity conservation and the Svalbard Global Seed Vault: Assessing the current status. PloS One 2013;8: e64146.

74. Cibrian-Jaramillo A, Hird A, Oleas N, et al. What is the conservation value of a plant in a botanic garden? Using indicators to improve management of ex situ collections. Bot Rev 2013;79:559-577.

75. Vernooy R. In the hands of many: A review of community gene/seed banks around the world. Community Seed Banks in Nepal: Past, Present, Future 2012:3-15.

76. Helicke NA. Seed exchange networks and food system resilience in the United States. J Environ Stud Sci 2015; 5:636-649. 
77. Purdy P, Wilson C, Spiller S, Blackburn H. Biobanking genetic resources: Challenges and implementation at the USDA National Animal Germplasm Program. Reprod Fertil Dev 2015;28:1072-1078.

78. Hockland S. Role and development of invertebrate collections in quality of identification for quarantine pests. EPPO Bull 2005;35:165-169.

79. Markow TA, O'Grady P. Drosophila: A Guide to Species Identification and Use. San Diego, CA: Academic Press; 2005.

80. Cook KR, Parks AL, Jacobus LM, Kaufman TC, Matthews K. New research resources at the Bloomington Drosophila Stock Center. Fly (Austin) 2010;4:88-91.

81. Zehr SM, Roach RG, Haring D, Taylor J, Cameron FH, Yoder AD. Life history profiles for 27 strepsirrhine primate taxa generated using captive data from the Duke Lemur Center. Sci Data 2014;1:140019.

82. McCouch S, Baute GJ, Bradeen J, et al. Agriculture: Feeding the future. Nature 2013;499:23-24.

83. Dedeurwaerdere T, Broggiato A, Louafi S, Welch E, Batur F. Global Scientific Research Commons under the Nagoya Protocol: Governing Pools of Microbial Genetic Resources. The Nagoya Protocol in Perspective: Implications for International Law and Implementation Challenges, Boston, MA. Brill/Martinus Nijhoff; 2012.

84. Roa C, Hamilton RS, Wenzl P, Powell W. Plant genetic resources: Needs, rights, and opportunities. Trends Plant Sci 2016;21:633-636.

85. Koehler-Rollefson I, Meyer H. Access and BenefitSharing of Animal Genetic Resources Using the Nagoya Protocol as a Framework for the Conservation and Sustainable Use of Locally Adapted Livestock Breeds. ABS Capacity Development Initiative-Implemented by the Deutsche Gesellschaft für Internationale Zusammenarbeit (GIZ) GmbH. 2014. Available at: www.fao.org/WAICENT/ faoINFO/AGRICULT/AGAInfo/programmes/en/genetics/ documents/ITWG_AnGR_8/side\&\# x02010 Accessed 2014.

86. Dedeurwaerdere T. Global microbial commons: Institutional challenges for the global exchange and distribution of microorganisms in the life sciences. Res Microbiol 2010;161:414-421.

87. Blackburn H, Plante Y, Rohrer G, Welch EW, Paiva S. Impact of genetic drift on access and benefit sharing under the Nagoya protocol: The case of the Meishan pig. J Anim Sci 2014;92:1405-1411.

88. Reeves PA, Panella LW, Richards CM. Retention of agronomically important variation in germplasm core collections: Implications for allele mining. Theor Appl Genet 2012;124:1155-1171.

89. Fritze D, Martin D, Smith D. Final report on the GBRCN Demonstration Project. Braunschweig, Germany: 2012 Contract No.: ISBN 978-3-00-038121-8.

90. Schüngel M, Stackebrandt E, Bizet C, Smith D. MIRRI-The Microbial Resource Research Infrastructure: Managing resources for the bio-economy. EMBnet J 2013;19:5-8.

91. Verslyppe B, De Smet W, De Baets B, De Vos P, Dawyndt P. StrainInfo introduces electronic passports for microorganisms. Syst Appl Microbiol 2014;37:42-50.

92. Gaudioso J, Gribble LA, Salerno RM. Biosecurity: Progress and challenges. J Assoc Lab Autom 2009;14:141-147.

93. Roberts B. Export controls and biological weapons: New roles, new challenges. Crit Rev Microbiol 1998;24:235-254.
94. Parkhill J, Wren B, Thomson N, et al. Genome sequence of Yersinia pestis, the causative agent of plague. Nature 2001;413:523-527.

95. Barabote RD, Xie G, Brettin TS, et al. Complete genome sequence of Francisella tularensis subspecies holarctica FTNF002-00. PloS One 2009;4:e7041.

96. Sharpton TJ, Stajich JE, Rounsley SD, et al. Comparative genomic analyses of the human fungal pathogens Coccidioides and their relatives. Genome Res 2009;19:17221731.

97. Secretariat $C$. The convention on biological diversity. In: Diversity TSotCoB (ed). Montreal: The Secretariat of the Convention on Biological Diversity; 1992. Available at: https://www.cbd.int/convention/text/ Accessed November 8, 2016.

98. McCluskey K. The Fungal Genetics Stock Center: From molds to molecules. Adv Appl Microbiol 2003;52: 245-262.

99. Nowogrodzki A. Biological specimen troves threatened by funding pause. Nature 2016;531:561.

100. Nowogrodzki A. Biological specimen troves get a reprieve. Nature News 2016. DOI: 10.1038/nature.2016.19995. Available at: www.nature.com/news/biological-specimentroves-get-a-reprieve-1.19995 Accessed November 8, 2016.

101. NIAID. Microbiology and infectious diseases biological research repository (MID-BRR). In: Services DoHaH (ed). National Institute of Allergy and Infectious Diseases; 2015. RFP-NIAID-DMID-NIHAI2015039. Available at: https://www.fbo.gov/utils/view?id=44be64647659a54243 bede966dc4db92 Accessed November 8, 2016.

102. National Science and Technology Council CoS, Interagency Working Group on Scientific Collections. Interagency Working Group on scientific collections. Scientific Collections: Mission-Critical Infrastructure of Federal Science Agencies. In: Policy OoSaT (ed). Washington, DC: US Office of Science and Technology Policy; 2009. Available at: https://usfsc.nal.usda.gov/sites/usfsc.nal.usda .gov/files/IWGSC_GreenReport_FINAL_2009.pdf Accessed November 8, 2016.

103. Campbell L, Betsou F, Garcia D, et al. Best practices for repositories-Collection, storage, retrieval and distribution of biological materials for research. Biopreserv Biobank 2012;10:79-161.

104. Kang S, Blair JE, Geiser DM, et al. Plant pathogen culture collections: It takes a village to preserve these resources vital to the advancement of agricultural security and plant pathology. Phytopathology 2006;96:920-925.

105. McCluskey K, Bates S, Boundy-Mills K, et al. Meeting report: 2nd Workshop of the United States culture collection network (May 19-21, 2014, State College, PA, USA). Stand Genomic Sci 2014;9:27.

106. Smith D. Culture collections over the world. Int Microbiol 2003;6:95-100.

107. Benson DA, Clark K, Karsch-Mizrachi I, Lipman DJ, Ostell J, Sayers EW. GenBank. Nucleic acids research 2015;43:D30.

108. Reichman JH, Uhlir PF, Dedeurwaerdere T. Governing Digitally Integrated Genetic Resources, Data, and Literature: Uncertain Legal Status of Microbial Genetic Resources in a Conflicted Geopolitical Environment. New York, NY: Cambridge University Press; 2016.

109. Bayh-Dole Act, Pub. L. No. 95-517 Stat. 94 Stat. 3015 (1980). 
110. Michener WK. Ten simple rules for creating a good data management plan. PLoS Comput Biol 2015;11:e1004525.

111. Association GAotWM. World Medical Association Declaration of Helsinki: Ethical principles for medical research involving human subjects. J Am Coll Dent 2014;81:14.

112. Herscovitch M, Perkins E, Baltus A, Fan M. Addgene provides an open forum for plasmid sharing. Nat Biotechnol 2012;30:316-317.

113. Shands HL. The US National Plant Germplasm System. Can J Plant Sci 1995;75:9-15.

114. Janssens D, Arahal DR, Bizet C, Garay E. The role of public biological resource centers in providing a basic infrastructure for microbial research. Res Microbiol 2010; 161:422-429.

115. Coenye T, Vandamme P. Bacterial whole-genome sequences: Minimal information and strain availability. Microbiology 2004;150:2017-2018.
116. Ward N, Eisen J, Fraser C, Stackebrandt E. Sequenced strains must be saved from extinction. Nature 2001; 414:148.

117. Prakash O, Shouche Y, Jangid K, Kostka JE. Microbial cultivation and the role of microbial resource centers in the omics era. Appl Microbiol Biotechnol 2013;97: $51-62$.

Address correspondence to: Kevin McCluskey, PhD

Fungal Genetics Stock Center Department of Plant Pathology Kansas State University Manhattan, KS 66506

E-mail: mccluskeyk@ksu.edu 